\title{
Voice and Vision in the Poetry of Eavan Boland
}

\author{
By Richard York \\ University of Ulster, Coleraine
}

Copyright (c) 2007 by Richard York. This text may be archived and redistributed both in electronic form and in hard copy, provided that the author and journal are properly cited and no fee is charged for access.

\begin{abstract}
Boland's poetry seeks to reconcile political and personal, the moment and duration, selfknowledge -seen as an exteriorisation of the self- and narration. It is therefore fundamentally concerned with aesthetics, especially in visual art, which however it views as a form of division and hypostatization of the moment, while it also seeks to place the intense moment of vision in the processes of time by recurrent images of transformation, anticipation, memory and loss; it is essentially elegiac, celebrating and lamenting the past and reflecting the constant presence of death within the everyday consciousness; hence the model of Vergil, and especially of the sixth book of the Aeneid, and of Irish song.
\end{abstract}

Key Words. Eavan Boland, self-knowledge, art, time, elegy, song, Vergil.

Resumen. La poesía de Boland compagina lo político y lo personal, el momento y lo permanente, el auto-conocimiento -en tanto que exteriorización del ser- y la narración. Se ocupa pues fundamentalmente de la estética, en especial en las artes visuales, a las que sin embargo considera una forma de división y reificación del momento, al tiempo que intenta insertar el momento intenso de la visión dentro de procesos temporales mediante imágenes recurrentes de transformación, anticipación, memoria y pérdida; es esencialmente elegíaca, en tanto que celebra y lamenta el pasado y refleja la constante presencia de la muerte en la conciencia cotidiana; de ahí el modelo virgiliano, en particular del sexto libro de la Envida, así como las canción irlandesa.

Palabras clave. Eavan Boland, auto-conocimiento, arte, tiempo, elegía, Virgilio.

One of Eavan Boland's finest poems is "The Art of Grief" (1995a: 208). It is, precisely, about art and grief, about their similarities and differences, and about their relation to time. "I saw a statue yesterday", the poem opens, firmly setting a tone of precise factuality and a time scale, a scale of recent everyday experience. But the statue is not exactly in time; like the speaker it is a middleaged woman, the product of aging, but the statue is "set and finished". And yet it is the product of a momentary act, "the same, indivisible act of definition /which had silenced her”. Indivisible; as with the concern with the atomic in the early poems, there is here the sense of the point at which process becomes irrelevant because no change is possible within a moment. It makes a change; it creates a division, a definition, a symbolic object. And it is perceived in an instant; if not in an indivisible moment, at least the contemplation of the statue takes place while the observer, 'caught by surprise', is preparing to get into her car, her keys still in her hand. It silences the grief-stricken woman, for the visual is instantaneous but language takes time (poems above all order our experiences in time). But within that instant there comes a 
recognition of a different time, the time of memory. The speaker recalls her mother's grief, which, unlike that of the statue, is conspicuously temporal, her unrhythmical sobs belying the regular unifying rhythm of verse, her private tears giving way to conversation and leaving her deciding to change the future; even her handkerchief is perceived as "the slow work of the moth". We live in time, but we can compress time into a moment. We create in a moment of division, but that moment is a compression of an age: the speaker longs to know

\section{the moment her sorrow entered marble - \\ the exact angle of the cut at which \\ the sculptor made the medium remember \\ its own ordeal in the earth, the aeons \\ crushing and instructing it until it wept itself \\ into inches, atoms of change.}

The ordeal in the earth is that of Proserpine, no doubt, the experience of death in the underworld, of the pain that comes into new life and becomes a reflection of the poet's own sensibility.

The poem brings together in a dense and lucid pattern some crucial concerns of the author. It seeks to define a moment; it shows the moment to be one of self-knowledge and it conceives of self-knowledge as exteriorization or reflection. It shows that momentary knowledge to be a product of art, of an essentially visual art (and in this respect Boland resembles many poets, not least in Ireland, who have devoted some of their verse to the description of visual art). But it questions that visual art, too. It conceives it as a violent hypostatization of a life which is also process, change in time, memory. Visual art is, in the words of the following poem in the collection (1995a: 210), "the terrible/ suspension of life". Boland is asserting, then, that poetry can also be narrative. And in this dual perspective "The Art of Grief” sums up a constant tension in Boland's work, the tension between the instantaneous visual discovery of the self and the exploration of experience in time. The issue is manifest in Object Lessons (1995b, 234), where she accuses traditional male "erotic" verse of "a concealed boast, a hidden brag about the power of poetry itself: that it could stop time". The female poet, on the contrary, must recognize that she can "age or fail or be simply mortal”. The female poem includes time; it is capable of "recording [...] the accurate detail of time passing, which might then become a wider exploration of its meaning" (1995b: 209). Haberstroh very rightly stresses the tension of image and temporality in Boland's work (Haberstroh 1993: 68,71,74); what needs to be emphasized is that image means not only "false representation", but also "static, momentary representation”.

Criticism of Boland has very naturally concentrated on what may be called the political aspects of her work, her engagement with feminism and nationalism; the poet's own prose writing does much to encourage this perspective. What will be argued here is that these involve an engagement with the past, conceived partly in public terms, but also as a discovery of the self and as an aesthetic stance, and that the richness and gravity of her work arises from these more private senses as well as from her public concerns. Her work is distinguished, it has been well said, by "a painterly consciousness, a keen, painful awareness of the shaping power of language, and a fundamental sense of poetic ethics" (Hagen and Zelman1991: 443); the painterly entails a static vision, language entails action in time, ethics embraces both the temporal and the atemporal, decision as well as sensibility. More specifically, it has been commented that "the source of Boland's poetic voice is [...] a force or power which emerges out of a particular individual experience - a singular moment in time" (Consalvo 1993: 103). Consalvo captures very pertinently the central importance of the singular moment; one should add that the moment may not always be individual in the most obvious sense of the word, and stress that what arises from it is a poetic force or power which may correspond to personal loss rather than personal energy; but the impulsion by which a vital selfhood emerges from a distinct moment is undoubtedly the mainspring of Boland's work.

The poet, then, knows herself in time and in a moment; her task is to reproduce the moment so as to reveal its intimate belonging to time. The point is further explored in "Lava Cameo" (1995a: 195). The poem is an expression of an experience also recounted in Object Lessons. The poet finds in a sale a lava cameo which recalls to her the one that belonged to her 
grandmother, and sees in its fabrication a series of acts which are "ironic and self-conscious": "to cut a human face into what had once flowed, fiery and devouring, past farms and livestock" (1995b: 33) - to cut form from movement. So the poem is a story - or perhaps it isn't; perhaps it is more of a rumour or hint. Or perhaps it is even a picture, something perceived in a moment with its colours and textures: wool, lace, silk and the lava cameo itself, "carved out of black, volcanic rock", carved as the statue in "The Art of Grief" is carved, the rock recalling a past of geological remoteness and violence. Certainly the poem starts by evoking a moment- perhaps an imagined moment,

\section{which can only be \\ justified if you think of it}

not as sculpture but syntax.

And that moment is set against what was to happen later, the death of man and woman, their loss to each other after a moment's touch, their loss to the poet their granddaughter. But something survives: the cameo itself, a detail in a visual composition at first, but finally the centre of the poem's attention, as it becomes an image of art itself, with

the obduracy of an art which can arrest a profile in the flux of hell.

Hell is again the source of the poem, the volcanic fire from which the lava rises, and again a sculpted permanence is arrested from it.

This sculpting has been part of Boland's imagination from the first: it is opposed in "Exhibitionist" (1995a: 68) where the moment of waking and of discovering the female body is seen as process and so "subvert[s]/ sculpture", while in "A Ballad of Beauty and Time" (1995a: 78) the work of the plastic surgeon, "a shape with a knife" is rejected as male suppression of the womanly body but is also questioned as repression of time and aging: "the sculptor ../ chiseling a nose" seeks to "bronze" a woman, to make a woman "fledged in stone", the wings of the classical statuary paradoxically demonstrating her fixity. The speaker refuses this denial of life, this capturing of "the last of youth/slumming in my pink skin”, asserting
I am the brute proof.

Beauty is not truth.

She is "the threat to your aesthetic" (and the rough and ready rhymes of these couplets suggest that she threatens any aesthetic). But the surgeon is given the last word. His sharpened skill (sharpened as a knife or a chisel is sharpened) arises from

my knowledge when -

above the honest flaw -

to lift and stay my hand

and say "let it stand".

The verse grows firmer; the speaker demonstrates the surety of the artist who creates and respects permanence, allows it to stand apart from himself. And there the dialogue ends, brute nature set against a perhaps complacent art. In "The New Pastoral” (1995a: 82), the tension is still more acute; the speaker lost, confused, eager to repair the destructions of time, finds in her memory only the recognition of " a rite/ I danced once on a frieze”. The speaker is a classic work of art, suggesting perhaps that Truth is, after all, Beauty; and of course her voice is a poem, and poems are works of art.

Art cuts; it is divisive. And so it relates to a whole dimension of Boland's thought, which is concerned with separateness, and often an aggressive separateness: the Irish pale (1998: 30), the sundering definition of dawn (1995a: 91), the maintenance of distance, aspect, on which our poetry depends (1995a: 125), the fiction made of distances (1995a: 170), the artist's gesture of turning her back to a painting to assert her distance from it (1998: 52); knowledge of the other is essentially difference. Precision is a matter of separation.

The moment of understanding is beautifully captured in “A Different Light” (1995a: 166), a poem about sudden change, in which the couple are caught unawares by a power cut, which puts an end to the images of gradualness, to the "slow arc" of a leaf, the vase "blooming / with shadows", the hourslong "soft brightness" of trees. The restoration of light is sudden; poet and husband look out at light being restored throughout the area: there is

that split second when you and I were, from a distance, a neighborhood on the verge of definition. 
But only on the verge. The splitting actually escapes them; they aren't quite identified with the exterior world. They miss the moment of sudden clarity, of precise vision, which remains a tantalising absence.

But there are other kinds of art which are more open to time, change, the corporeal, and which do allow the self to approximate to the world outside. The painters Boland is drawn to are those conscious of the beauty of light and surfaces and of the stillness of the moment: Renoir, Canaletto, Chardin, Van Eyck. (On Boland's relation to painting, see Johnston1997: 275-9, though one may disagree with Johnston's view that she favours the visual over the auditory). The Arnolfini Marriage, in "Domestic Interior" (1995a: 978), encapsulates a life in the glow of expectancy: the bride is

burnished, fertile, on her wedding day, interred in her joy.

She manifests

a quiet search for attention
like the unexpected shine
of a despised utensil.

The reader recognises with pleasure the calm beauty of the painting. Van Eyck seems the perfect example of the artist who, in the words of another poem, can "bless the ordinary" and "sanctify the common" (1995a: 123).But Boland still withholds her consent. The bride is interred in happiness; and the full sense of that interment, the paradox of pleasure and deathliness, emerges from the earlier line on the artist's "worm of permanence"; so the poem turns to the poet's own marriage,

a way of life

that is its own witness,

that doesn't need art, doesn't need the intrusive consciousness of the painter, a life that is

$$
\begin{aligned}
& \text { shrugged and settled } \\
& \text { in the sort of light } \\
& \text { jugs and kettles } \\
& \text { grow important by. }
\end{aligned}
$$

A life like that of the despised domestic utensil, in other words. The lines are very fine in their calm and meditative acceptance of the everyday. But they leave a complication; this poem has itself achieved the transfiguration Van Eyck has offered in the past; Boland's marriage becomes beautiful in a work of art, though not the art of a stranger (like the rather threatening stranger Degas, 1995a: 75). She reflects her happiness in her writing; and we can't forget that one of the most striking components of the Van Eyck painting is a mirror, since Boland introduces it early in the text: "the mirror weds her". The mirror, the instrument of visual self-awareness, is the source of order and dignity; and there are many mirrors in Boland's work

Unlike paintings, poems can capture change; they are, as "Lava Cameo" indicates, a syntax and not a sculpture. What they can capture is

$$
\begin{aligned}
& \text { the hour of change, of metamorphosis, } \\
& \text { of shape-shifting instabilities; }
\end{aligned}
$$

she is especially aware of "the in-between,/ neither here-nor-there hour of evening" (1995a: 114). The myths of which she is so fond - and from which she may seek to escape as myth threatens to be fixity - are myths of transformation: Daphne, the children of Lir, Etain. And transformation can be perceived every day in the movement of light that so preoccupies the poet, in dawn and dusk. One may have the impression that Boland is given to writing in the early evening; or if this is not literally true, at least it seems that morning and evening are the times that most reflect the integration in a changing world that she aspires to.

The conception is explored with great delicacy in "This Moment" (1995a: 182). The poem presents "A neighborhood./At dusk". What dusk means is stars and moths: familiar enough aspects of evening, they are complemented by the more impressionistic or imaginative sense of the growth of fruit (does it grow specially at night, one may wonder? Or does it just seem as if it ought to, because the growth may appear so gradual, discreet, uncaused?). Announced towards the beginning of the poem, these things come to full activity in the last lines:

Stars rise.

Moths flutter.

Apples sweeten in the dark. 
There is beauty and fulfilment in these nocturnal processes. But the first fascination of the poem is with the anticipation of night, the moment before fulfilment, when

\section{Things are getting ready \\ to happen \\ out of sight,}

a readiness sensed, obviously, but not directly perceived by the poet. And the moment of transition is a moment of love:

A woman leans down to catch a child who has run into her arms this moment.

This moment, a moment which is "potent and emblematic and true", like that of the lost poem in Object Lessons (1995b: 241): the emphasis of the line division proudly insists on the observer's grasping of the immediate, but the structure of the whole poem places the moment in a process of time, just as it places the figures in a landscape.

The moment does not always attain such grace. In "What we have lost" (1995a: 159) "the moment happens, hangs fire, leads nowhere" - except to darkness and lost speech. And the unity achieved within the poem is often a melancholy one. "The Unlived Life" (1995a: 108) makes the point. Talking to a neighbour about the female craft of patchwork, the speaker suddenly envisages another life, the life of the American West, where the craft was specially developed, with its nostalgia for the elsewhere symbolised by the train, "iron omen/ of another life passing", and then returns to think of home and the formalities of a symmetrical art. She notes as she leaves her friend that it is bed-time for children (recalling the obligations of family love) and she ends with a vision of garden and star from her door: complex perspectives, in which darkness permits a dialectic of merging and uniqueness,

\author{
while day backed into night \\ and separate darks blended the shadows, \\ singling a star out of thin air
}

as we went in.

Solitude and friendship, the neighbour and the family, the present and the imagined, the controlled life and the alien distances, the sudden and the gradual: the poem delicately makes its own pattern out of them, asserting the accessibility in thought of what is absent in reality.

The moment may be a moment of precariousness. Johnston aptly speaks of the "fragile momentariness" of her writing (Johnston 1997: 278), and this is apparent throughout the poems. The moment may be a recognition of mortality. The moment of truth for the moths, in the poem of that name (1995a: 189) is the moment of dark in which they are attracted to their destruction. The author, like them, is perishing

on the edge and at the threshold of

the moment all nature fears and tends towards:

the stealing of the light.

The sense of the fragility of the moment is particularly apparent in the poem "Object Lessons" (1995a: 139), as is the ambiguity of presence and loss in the mind. The object of the lesson is a coffee mug decorated with an ancient hunting scene, suggestive of picturesque romance, with "A lady smiling as the huntsman kissed her". The couple, for whom the mug is a familiar domestic utensil, see it with naïve optimism:

$$
\begin{aligned}
& \text { the way land looks before disaster } \\
& \text { strikes or suffering } \\
& \text { becomes a habit } \\
& \text { was not a feature } \\
& \text { of the history we knew. }
\end{aligned}
$$

The lines elusively slip from sense to sense: before disaster, or before disaster strikes? before suffering or before suffering becomes a habit? Most crucially, the tragic anticipation depicted here at first seems to be asserted as part of the depicted scene, but then it proves that it is being denied (it is not a feature). "The poem hesitates", Boland comments elsewhere (1995a: 133); hesitation is a dramatic presentation of anticipation, and here a partial anticipation, for disaster is about to strike. But even that disaster is not quite presented; the focus is on the anticipation of disaster, or perhaps the anticipation of the anticipation of disaster: the poem focuses on the enjoyment of the moment before they learnt that 


\author{
the details of \\ this pastoral were merely \\ veiled warnings \\ of the shiver \\ of presentiment with which \\ we found the broken pieces...
}

And the discovery focuses their attention on an uncompleted task:

the floorboards you and I had sworn

to sand down and seal

with varnish.

A strange emphasis again in that last line; the varnish a hard, excluding surface alien to the shifting in time that characterises the object recalled in memory, the lost object that depicts unfulfilled sport and recalls unfulfilled duty.

For it is in memory that the depth of the moment is most grasped (the role of memory in Boland is discussed by several critics, notably Dawe 1992:179). The moment of transformation may be a moment of loss, as in "Suburban Woman: A Detail" (1995a: 111-3) where dusk brings a blending with the night and a recognition of the outside world as a reflection of the self, the tree that in true mythical style was a woman once; this blending is seen as a bewildering loss of definiteness, leaving only a sense that darkness

$$
\begin{aligned}
& \text { has begun } \\
& \text { softening the definitions } \\
& \text { of my body - }
\end{aligned}
$$

(and again the line ending at "begun" gives a discreet ambiguity: darkness has begun, absolutely, and one of its characteristics is that it softens, or it has begun the softening process). This may be a welcome transcendence of the self, by contrast with the hard, cutting isolation of the sculptural self; but it leaves the sense also that the flesh - with all its fears and terrors - still calls Remember us. Identity is not abandoned; memory retains even what is painful in it.

Or perhaps especially what is painful. The remembered moments are very frequently moments of pain or loss, at least in contemplation. "The Bottle Garden” (1995a: 111) takes the speaker back to her youth, when as a gangling schoolgirl she read of the shadowy world of the dead in Virgil's Aeneid, sitting in the darkening room of her school library; she discovers "the improvised poetic of imprisoned meanings" as she faintly recalls the precise sensation of her school blouse "riding up at the sleeves". She is now "past the middle way"; past the time when Dante, guided by Virgil, found a new faith in his experience of the beyond. She seeks a way, as Dante did, but a secular way, and finds it in the memory of youth and a melancholy poetry, a memory of complex and indistinct sensation, only half aware of the actual, her school clothes and the lights outside, submerged in the moment which changes from day to night as it merges into the deathly past culture of the classical underworld, and at the same time animates it. The paradox is underlined by the play of sounds: the sense of the Aeneid is imprisoned, constrained by a dead language, as the dead are imprisoned in the underworld, but as the words come to merge with the sensibility of the reader they become part of her improvised response; reading transcends temporal division.

"The Latin Lesson" (1995a: 144), too, recalls the school days of discipline, orthodoxy, effort and culture - a culture that brings the beauty and the melancholy of Virgil's visit to the dead, a culture of the imagination which replaces the Easter light, the storm light, of reality by the shadow bodies of the underworld (but Easter is the time of the resurrection from Hell, a resurrection known, mythically at least, to Christ, Dante, Virgil and Proserpine). The poem constitutes a dense and slightly ironic- unity; the eucalyptus leaves (familiar from other Boland poems and her schoolday memories in Object Lessons) are used by the priest as a training in orthodox contemplation of the goodness of God; they are not crushed to release their distinctive scent, but the words of the epic are crushed to release the imagination into death. The dead long for the far shore; so far the poem echoes Virgil; but whereas in Virgil the shore they long for is the ultimate admission to the beyond, in Boland it is a return to the domestic, to "the small usefulness of a life". The speaker is tempted by their commitment to the other world, the world of darkness, but she has also an attachment to everyday reality - not exactly to the utilitarian home, but to the "civil tongue" her teachers call for. Is poetry a civil tongue? It 
is a tongue, it seems, which relates the civil, the mannerly, to the extreme. It is a sort of language which displays the continuity of the given and the strange, of the acceptance of the social and of the dissipation of the self. Here it does so through a dialectic of light, a gamut of times and a counterpoint of voices. The glittering light of Easter, of the tree, of nature and the storm light of the sea are set against the shadowy darkness of the afterlife; the sharp definition of time by the school bell balances the longer duration of the memory of yesterday's talk, the patient effort of reading a foreign language and the repeated extraction of sense from the words, the fascination of imagined timelessness; the sharp authority of the nun and the mild, ingratiating persuasion of the priest contrast with the words on the page which are objects of the reader's use and with her fantasised hailing of the dark boatman, Charon. The discovery of death is a kind of movement into freedom as well as a movement into the dark and a discovery of loss. School education both disciplines and liberates; the poem -like the memory from which poetry arises- formulates the duality of a moment in which power and self-abandon delicately coexist.

This recreation of the past is, paradoxically, an experience of loss: much in Boland's writing implies that poetry is precisely a narrating of loss, of the pace at which loss is felt and of the way we come to see what we have lost. Luftig has well said that, like Adrienne Rich, she qualifies the immediacy of her writing by "repeated acknowledgements of distance and belatedness" (Luftig, 1993: 65). Her poetry, in other words, is elegiac. The point is made most explicitly in "On the Gift of 'Birds of America' by John James Audubon" (1995a: 140), a poem in which one may still sense the distant presence of the Aeneid Book VI. On the face of it, the speaker has gained something: she has been given a book, and is thanking the donor for it. The poem dramatizes a personal contact, and there seems also to be a visual contact with the very precisely depicted birds of Audubon's illustrations: the redshouldered hawk, the scattering partridges, "the broad-winged one poised on the branch lof a pignut “... (What is a pignut? The precision of naming may impress and perhaps puzzle European readers, at least.) But that presence of the vital energy of the birds is really an absence; these brief visions of vital energy -the instant of the frightening descent of the hawk, the momentary poise on the branch, "the plummet of the tern"- are abstracted by the act of reproduction: no longer real birds, they are no more than an inference which we follow. We need to imagine the light in which they thrived. "Inference" and "imagine" are both powerfully stressed, each constituting almost the whole of the third line of succeeding three line stanzas, and the process of meditation and elucidation is made perceptible in the sinuous patterning of the long sentence which occupies the first 20 lines of the poem, with their discreetly emphatic rhythmic variations. The visual is subject to a syntax; Audubon's immediate perception is replaced by our historic culture in which we are aware that the birds no longer exist; what we imagine is

\section{the franchise of light these camphor-coloured wings opened out \\ once with and are at such a loss for now.}

The tension of joy, freedom, accurate perception on one hand and of transience of the other is beautifully captured in the lines; and then it is named. This is elegy:

the celebration of an element

which absence has revealed: it is our earthliness

we love as we look at them, which we fear to lose, which we need

this re-phrasing of the air, of the ocean to remind us of....

Elegy relates the outer world to ourselves; in the elegiac mood, the book is one more mirror. And, like Virgil's dead, what we learn of ourselves is our earthliness, our physicality, shared with the dangerous and fragile birds, the dichotomy within us between the process of aging and the preservation of experience in thought. And that preservation is finally asserted in memory; the "re-phrasing", the transformation of the real, recalls another moment, one which brings the speaker back to the donor of the book, with whom she shares the memory of two swans who flew over them in Co Clare, leaving them, in the last line, "rooted to the spot", attached to the Irish 
earth, in contemplation of those birds of Irish myth, the patient exploration of the poem concluding in an instant of stillness.

The point is more briefly made in "We are Human History. We are not Natural History" (1995a: 155), where

light
was short-lived and elegiac as
the view from a train window of
a station parting, all tears.

The poem has "singled out" an evening, "chosen" it from the accumulation of evenings which make up "the stashed-up debris of old seasons" - on other words has performed the act of artistic selectivity; and this is elegiac, recalling the brief glimpse of a separate sorrow. Poetry, then, is a matter of cadences (we recall that the directly expressed grief of the speaker's mother in "The Art of Grief" "has no cadence"). Cadence, rhythm and falling, is the art of the dispossessed Irish bard, as he falls into the darkness of sleep (1998:13). Cadence is what makes poetry a confrontation of the human condition:

$$
\text { make us human }
$$

in cadences of change and mortal pain

and words we can grow old and die in (C206).

And perhaps exile too belongs to this same elegiac sense of language, in which language becomes “a habitable grief” (1998: 29).

The sense of loss, of shared deprivation, is at its most powerful in "The Journey" (1995a: 20); inspired again by Book VI of the Aeneid (as noted by, amongst others, Jody AllenRandolph 1993:19) but also by Sappho, the woman poet who replaces Virgil as the guide to the underworld and becomes a motherfigure for the author (the specific echo is of the Hymn to Aphrodite), it recounts an exploration of the dead. It begins as darkness falls. The speaker turns from her reading, regretting the modern-day gap between language and reality, and in particular the inability of poets to deal with medical progress and their attachment to the symbols of classicism (but Boland's own attachment to the classics is already apparent in the Virgilian epigraph). She turns to something like a dream and in silence accompanies
Sappho on the initiatory journey downwards, during which light "went on/failing" (again that brief ambiguity of the line-ending) until finally they come to

$$
\text { a sudden rest }
$$

beside a river in what seemed to be an oppressive suburb of the dawn.

The relationship of this to the rest of Boland's work is clear enough; suddenness, the river, the dawn, the suburb, no longer a place of domestic order but a place of terror. Slowly she makes out shadowy figures and realises that these are the dead mothers of the past; of a time when cholera, typhus, croup, diphtheria, plague were rife. The observer once more finds herself reflected in the observed; the mothers have shared her ordinary love of children, they have enjoyed dusks and springs. Cut off from them by "the melancholy river", she asks to be their witness, but Sappho declares that their being is

$$
\text { beyond speech, }
$$

beyond song, only not beyond love;

'remember it, you will remember it,

[...] I have brought you here so you will know forever

the silences in which are our beginnings.

The poet awakes, to find her children safely sleeping out the last of the dark, and she weeps. Sappho's guidance is paradoxical; the suffering of the women of history is not beyond speech, for this poem is precisely a way of speaking of it. That way of speaking is shown as a memory of an origin, itself beyond words; the specific imagined scene is an essence of suffering femininity. The origin becomes language in narrative, but this is a narrative of an experience in which nothing changes, an experience alien to time, a dream which is not only a sequence of discoveries, a process of learning, an enrichment of the capacity for love, but also an empty interlude in which nothing happens. As she wakes, she finds rain, and the rain is "grief in arrears"; it is saved up from the alienated experience of the dream, just as her grief within the dream is an arrears of the suffering of the past (so that the poem is, after all, a praise of medical progress, by inversion: the antibiotics have relegated child death, largely, to historical distance). 
We may conclude by considering briefly the introductory poem to In a Time of Violence, "The Singers" (1995a: 173). Boland told an interviewer, "I found my voice where I found my vision, and I found my vision where I lived" (Consalvo 1993: 103). When she considers the same concepts in verse, her emphasis is rather different; the vision is very precisely a momentary recognition, and it is located in the past, where other people lived. The poem is concerned with women, with Ireland, with hardship. It is concerned with a moment, not perhaps a real moment, but a moment the poet imagines, a little sceptically: a moment of revelation in which the women discover that the harsh exterior world of rain and ocean is identical with their own feeling of home, that the outside world complements them, or they complement the outside world. They respond to this revelation in song, which expresses danger but also rejoicing, and above all perpetuates the discovery that self and environment are interconnected. This -if it exists- is a true art, one which both expresses the individual and also reflects time, continuation, darkness, exhaustion, and which accepts these things. It is an art which asserts their joy in "finding a voice where they found a vision".

\section{Note}

I should like to thank Dr Bruce Stewart for bibliographic help through Eirdata (www.pgileirdata.org). This site offers much useful information on Boland, including critical comment.

\section{Works Cited}

Allen-Randolph, Jody. 1993. “Private worlds, public realities”. Irish University Review, 23,1. 5-22.

Boland, Eavan. 1995a.Collected Poems. Manchester: Carcanet. .1998. The Lost Land. Manchester: Carcanet. .1995 b. Object Lessons. Manchester: Carcanet.

Consalvo, Deborah McWilliams. 1993. "In Common Usage: Eavan Boland’s poetic voice”. Eire-Ireland, $28,2$. 100-115.

Dawe, Gerald. 1992. “The suburban night: on Eavan Boland, Paul Durcan and Thomas McCarthy”. Contemporary Irish Poetry. Ed. Elmer Andrews. London: Macmillan.168-193.

Haberstroh, Patricia Boyle. 1993. "Woman, artist and image in Night Feed", Irish University Review, 23,1. 6774.

Hagen, Patricia L. and Zelman, Thomas W. 1991. "We were never on the scene of the crime: Eavan Boland's repossession of history”. Twentieth Century Literature, 37,4. 442-53.

Johnston, Dillon. 1997. Irish Poetry after Joyce, $2^{\text {nd }}$ ed. Syracuse: Syracuse UP,.

Luftig, Victor. 1993. “Adrienne Rich, Eavan Boland”. Irish University Review, 23,1.57-66 